Pacific Journal of Mathematics

STABILITY OF LINEAR DIFFERENTIAL EQUATIONS WITH 


\title{
STABILITY OF LINEAR DIFFERENTIAL EQUATIONS WITH PERIODIC COEFFICIENTS IN HILBERT SPACE
}

\section{Gert Almkvist}

\begin{abstract}
In this paper we study the stability of the solutions of the differential equation$$
u^{\prime}(t)=A(t) \cdot u(t)
$$

for $t \geqq 0$ in a separable Hilbert space. It is assumed that $A(t)$ is periodic with period one and satisfies the following symmetry condition: There exists a continuous constant invertible operator $Q$ such that

$$
A(t)^{*}=-Q \cdot A(t) \cdot Q^{-1} \quad \text { for all } t \geqq 0 \text {. }
$$

We use a perturbation technique. Let $A(t)=A_{0}(t)+B(t)$ where $A_{0}(t)$ is compact and antihermitian for all $t$. We denote by $U_{0}(t)$ the solution operator of $u^{\prime}(t)=A_{0}(t) u(t)$. It is shown that (1) is stable if $B(t)$ satisfies a certain smallness condition involving the distribution of the eigenvalues of $U_{0}(1)$ and the action of $B(t)$ on the eigenvectors of $U_{0}(1)$. The results can be applied to the second order equation

$$
y^{\prime \prime}+C(t) y=0
$$

where $C(t)$ is selfadjoint for all $t$.

Throughout this paper we consider the differential equation (1) where $u$ is a function from the positive reals, $\mathbf{R}^{+}$, into a separable Hilbert space $X$ with norm $\|x\|=(x, x)^{1 / 2} . \quad A$ is a function from $\mathbf{R}^{+}$ into $B(X)$, the algebra of continuous linear operators on $X$. We assume that $A(t)$ is Bochner integrable on every finite subinterval of $\mathbf{R}^{+}$. Then for a given initial value $u(0)$, there exists a unique solution of (1) (see [4, p. 521]).

Further we always assume that $A(t)$ is periodic. It is no restriction to assume that the period is one, that is $A(t+1)=A(t)$ for all $t \in \mathbf{R}^{+}$.

The equation (1) is said to be stable if for every initial value $u(0)$, there exists a constant $M$, such that $\|u(t)\| \leqq M$ for all $t \in \mathbf{R}^{+}$. It is convenient to study the equation

$$
U(t)^{\prime}=A(t) U(t), \quad U(0)=I
$$

in $B(X)$. Using the principle of uniform boundedness it is easily seen that (1) is stable if and only if the solution of (2) is bounded. 
Let

$$
\Phi(A)=\lim _{\infty \rightarrow+0} \alpha^{-1}(\|I+\alpha A\|-1)
$$

denote the Gateau differential of $A$. When $X$ is a Hilbert space $\Phi(A)$ can be calculated by the formula $\Phi(A)=\sup _{\|x\|=1} R e(A x, x)$

Proposition 1. If $\int_{0}^{1} \Phi(A(t)) d t \leqq 0$, then (1) is stable.

Proof. Let $n$ be the greatest integer $\leqq t$. Then using [1, Th. 4] we get

$$
\begin{gathered}
\|U(t)\| \leqq \exp \int_{0}^{t} \Phi(A(s)) d s \leqq \exp \left(n \int_{0}^{1} \phi(A(s)) d s\right) \cdot \exp \int_{0}^{t-n} \phi(A(s)) d s \\
\leqq \exp \int_{0}^{1}|\Phi(A(s))| d s
\end{gathered}
$$

which ends the proof.

From now on we assume that $A(t)$ satisfies the following symmetry condition:

There exists a constant continuous operator $Q$ such that $Q^{-1}$ is continuous and

$$
A(t)^{*}=-Q A(t) Q^{-1}
$$$$
\text { for all } t \geqq 0 \text {. }
$$

Here $A^{*}$ denotes the adjoint of $A$.

Proposition 2. Condition (S) is equivalent to

$$
U(t)^{*}=Q U(t)^{-1} Q^{-1}
$$

for all $t \geqq 0$.

Proof. We have $U^{*}(0) Q U(0)=Q$ because $U(0)=I$. But

$$
\frac{d}{d t}(U(t) * Q U(t))=U(t)^{*} A^{*}(t) Q U(t)+U(t)^{*} Q A(t) U(t)=0
$$

if and only if

$$
A^{*}(t) Q+Q A(t)=0 \text {. }
$$

Let $\sigma(U)$ be the spectrum of $U$. From Proposition 2 it follows that $\sigma\left(U^{*}(t)\right)=\sigma\left(Q U^{-1}(t) Q^{-1}\right)=\sigma\left(U^{-1}(t)\right.$ that is $\lambda \in \sigma(U(t))$ implies $\bar{\lambda}^{-1} \in \sigma(U(t))$.

Proposition 3. If $Q$ is positive definite, then (1) is stable.

Proof. $Q$ has a positive definite square root $S$, that is $Q=S^{2}$. Moreover $S^{-1}$ exists and is continuous. From Proposition 2 we get 


$$
U^{*}=S^{2} U^{-1} S^{-2}
$$

and after some calculations $\left(S U S^{-1}\right)^{*}=\left(S U S^{-1}\right)^{-1}$, that is $S U S^{-1}$ is unitary and hence $\|U(t)\| \leqq\|S\| \cdot\left\|S^{-1}\right\|$ for all $t \geqq 0$.

The uniqueness of the solution of (2) implies that

$$
U(n+t)=U(t) U(1)^{n} \quad \text { for } n=1,2, \cdots
$$

Hence (1) is stable if and only if there exists a constant $M$ such that

$$
\left\|U(1)^{n}\right\| \leqq M \quad \text { for } n=1,2, \cdots
$$

Since $\left\|U(1)^{n}\right\| \geqq(\nu(U(1)))^{n}$, where $\nu$ is the spectral radius, it follows that $\sigma(U(1)) \subset\{\lambda ;|\lambda| \leqq 1\}$ is necessary for the stability of (1). When (S) is satisfied $\sigma(U(1))$ is symmetric about the unit circle and hence $\sigma(U(1)) \subset\{\lambda ;|\lambda|=1\}$ is necessary.

Now we study the stability of (1) with a perturbation method, due to G. Borg [3] in the finite dimensional case. In order to state the next theorem we introduce some notations. Let the equation be

$$
u^{\prime}(t)=\left(A_{0}(t)+B(t)\right) u(t)
$$

We assume that

(a) $A_{0}(t)$ and $B(t)$ are periodic with period one.

(b) $A_{0}(t)$ is compact and antihermitian $\left(A_{0}(t)^{*}=-A_{0}(t)\right)$ for all $t$.

Let further $U_{0}(t)$ be the unique solution of $U_{0}^{\prime}(t)=A_{0}(t) U_{0}(t)$, $U_{0}(0)=I$. Suppose that

(c) $U_{0}(1)$ has only simple eigenvalues, $\lambda_{n}$, all $\neq 1$.

(d) $A_{0}(t)+B(t)$ satisfies condition (S).

Let further $e_{n}$ be the eigenvector with norm one of $U_{0}(1)$ corresponding to the eigenvalue $\lambda_{n}$. Put

$$
\begin{aligned}
b_{n}^{2} & =\int_{0}^{1}\left\|B(t) U_{0}(t) e_{n}\right\|^{2} d t \\
K & =\int_{0}^{1} \exp \left[2 \int_{t}^{1} \Phi(B(s)) d s\right] d t \\
r_{n} & =2^{-1} \inf _{k \neq n}\left|\lambda_{n}-\lambda_{k}\right| .
\end{aligned}
$$

THEOREM. If (a), (b), (c), (d) and

$$
K \cdot \sup _{k} \sum_{n=1}^{\infty} b_{n}^{2}\left(\left|\lambda_{k}-\lambda_{n}\right|-r_{k}\right)^{-2}<1
$$


and

$$
\sum_{n=1}^{\infty} b_{n}^{2} r_{n}^{-2}<\infty
$$

are satisfied, then (3) is stable.

REMARK 1. The theorem is true if $K$ and $b_{n}$ are replaced by

$$
K^{\prime}=\exp \left\{2 \max _{0 \leq t \leq 1} \int_{t}^{1} \Phi(B(s)) d s\right\}, \quad b_{n}^{\prime}=\int_{0}^{1}\left\|B(t) U_{0}(t) e_{n}\right\| d t .
$$

It is easily seen that $K \leqq K^{\prime}$ but $b_{n}^{\prime} \leqq b_{n}$.

REMARK 2. If $X$ is finite dimensional, then condition ( $f$ ) is automatically fulfilled.

REMARK 3. $K \cdot \sum_{1}^{\infty} b_{n}^{2} r_{n}^{-2}<1$ implies both (e) and (f).

Proof of the theorem. The rather lengthy proof is divided in eight parts.

(i) $U_{0}(t)$ is unitary for all $t$.

A calculation shows that $U_{0}(t)^{-1}=V(t)^{*}$ where $V$ is the unique solution of $V^{\prime}=-A_{0}^{*}(t) V, V(0)=I$. But since $-A_{0}^{*}=A_{0}$ it follows that $U_{0}(t)^{-1}=U_{0}(t)^{*}$.

(ii) $U_{0}(1)-I$ is compact.

We have $U_{0}(1)-I=\int_{0}^{1} A_{0}(t) U_{0}(t) d t$. The integral is compact because it is the limit of compact operators of the form $\sum_{i=1}^{n} A_{0}\left(t_{i}\right) U_{0}\left(t_{i}\right) \Delta t_{i}$.

From (i) and (ii) we conclude that $\left\{e_{n}\right\}_{1}^{\infty}$ is an orthonormal set and indeed a basis because $U_{0}(1)-I$ is compact and 1 is not an eigenvalue of $U_{0}(1)$. Further $\lim _{n \rightarrow \infty} \lambda_{n}=1$. Since $U_{0}(t)$ is unitary

$$
\left\|U_{0}(t)\right\|=\left\|U_{0}(t)^{-1}\right\|=1 \text { for all } t \text { and }\left|\lambda_{n}\right|=1 \text {. }
$$

Put $W(t)=U(t)-U_{0}(t)$. Further it is convenient to write $U(1)=U, \quad U_{0}(1)=U_{0}$ and $W(1)=W$. Let $C_{k}$ be the circumference of a circle with center $\lambda_{k}$ and radius $r_{k}$.

(iii) $R_{\lambda}=(\lambda I-U)^{-1}$ exists if $\lambda \in \bigcup_{1}^{\infty} C_{k}$.

Put $R_{\lambda}^{0}=\left(\lambda I-U_{0}\right)^{-1}$. For a $\lambda$ such that $R_{\lambda}^{0}$ and $\left(I-W R_{\lambda}^{0}\right)^{-1}$ 
exist, we have

$$
R_{\lambda}=R_{\lambda}^{0}\left(I-W R_{\lambda}^{0}\right)^{-1}
$$

It is clear that $R_{\lambda}^{0}$ exists whenever $\lambda \in \bigcup_{1}^{\infty} C_{k}$ and if $\left\|W R_{\lambda}^{0}\right\|<1$ it follows that $R_{\lambda}$ exists. Since $\left\{e_{n}\right\}_{1}^{\infty}$ is an orthonormal basis it follows that

$$
\left\|W R_{\lambda}^{0}\right\|^{2} \leqq \sum_{1}^{\infty}\left\|W R_{\lambda}^{0} e_{n}\right\|^{2}
$$

But

$$
\left\|W R_{\lambda}^{0} e_{n}\right\|=\left|\lambda-\lambda_{n}\right|^{-1} \cdot\left\|W e_{n}\right\|
$$

since

$$
R_{\lambda}^{0} e_{n}=\left(\lambda-\lambda_{n}\right)^{-1} e_{n} .
$$

One verifies that $W(t)$ satisfies the equation

$$
W^{\prime}(t)=\left(A_{0}(t)+B(t)\right) W(t)+B(t) U_{0}(t)
$$

which has the solution

$$
W=W(1)=\int_{0}^{1} U(1) U(s)^{-1} B(s) U_{0}(s) d s
$$

Then we get

$$
\left\|W e_{n}\right\| \leqq \int_{0}^{1}\left\|U(1) U(s)^{-1}\right\| \cdot\left\|B(s) U_{0}(s) e_{n}\right\| d s .
$$

From Theorem 4 in [1] we find

$$
\left\|U(1) U(s)^{-1}\right\| \leqq \exp \int_{s}^{1} \Phi\left(A_{0}(t)+B(t)\right) d t .
$$

But $\Phi\left(A_{0}(t)+B(t)\right)=\Phi(B(t))$ since $A_{0}(t)$ is antihermitian. We finally get

$$
\begin{aligned}
\left\|W e_{n}\right\|^{2} & \leqq\left\{\int_{0}^{1} \exp \left[\int_{s}^{1} \Phi(B(t)) d t\right]\left\|B(s) U_{0}(s) e_{n}\right\| d s\right\}^{2} \\
& \leqq \int_{0}^{1} \exp \left(2 \int_{s}^{1} \Phi(B(t)) d t\right) d s \cdot \int_{0}^{1}\left\|B(s) U_{0}(s) e_{n}\right\|^{2} d s=K \cdot b_{n}^{2}
\end{aligned}
$$

From condition (e) we conclude that

$$
\begin{aligned}
\sum_{1}^{\infty}\left\|W R_{\lambda}^{0} e_{n}\right\|^{2} & \leqq K \cdot \sum_{1}^{\infty} b_{n}^{2}\left|\lambda-\lambda_{n}\right|^{-2} \\
& \leqq K \cdot \sup _{k} \sum_{n=1}^{\infty} b_{n}^{2}\left(\left|\lambda_{k}-\lambda_{n}\right|-r_{k}\right)^{-2}<1
\end{aligned}
$$


and hence $\left\|W R_{\lambda}^{0}\right\|<1$ for all $\lambda \in \bigcup_{1}^{\infty} C_{k}$. Thus we have shown that $R_{\lambda}$ exists if $\lambda \in \mathrm{U}_{1}^{\infty} C_{k}$.

\section{(iv) $U-I$ is compact.}

From (iii) it follows that $\sum_{1}^{\infty}\left\|W e_{n}\right\|^{2} \leqq K \sum_{1}^{\infty} b_{n}^{2}<\infty$ since (e) implies that $\sum_{1}^{\infty} b_{n}^{2}<\infty$. Hence $W$ belongs to the Schmidt class, cf. [5], and is compact. Further $U-I=\left(U_{0}-I\right)+W$ is compact since $U_{0}-I$ is compact (ii).

Put $D_{n}=\left\{\lambda ;\left|\lambda-\lambda_{n}\right|<r_{n}\right\}$

(v) U has exactly one eigenvalue, $\alpha_{n}$, in $D_{n}$ and $\alpha_{n}$ is simple.

Since $U-I$ is compact and $1 \notin D_{n}$ it follows that there is only a finite number of eigenvalues of $U$ in $D_{n}$.

Now it is convenient to introduce a parameter $\mu$ in the equation. Thus we study $U^{\prime}=\left(A_{0}(t)+\mu B(t)\right) U, U(0)=I$ where $0 \leqq \mu \leqq 1 . \quad$ A simple calculation shows that $R_{\lambda}(\mu)$ is a continuous function of $\mu$. Hence the projection

$$
E_{n}(\mu)=(2 \pi i)^{-1} \int_{\sigma_{n}} R_{\lambda}(\mu) d \lambda
$$

is also continuous in $[0,1]$. Further we can find a partition

$$
0=\mu_{1}<\mu_{2}<\cdots<\mu_{k}=1
$$

such that

$$
\left\|E_{n}\left(\mu_{\nu+1}\right)-E_{n}\left(\mu_{\nu}\right)\right\|<(2 M)^{-1} \quad \text { for } \nu=1,2, \cdots, k,
$$

where $M=\max _{0 \leq \mu \leq 1}\left\|E_{n}(\mu)\right\|$. According to a well known lemma (see [6, p. 424]) it follows that $\operatorname{dim} E_{n}\left(\mu_{\nu+1}\right) X=\operatorname{dim} E_{n}\left(\mu_{\nu}\right) X$ if both sides are finite. This is the case here because $U(\mu)-I$ is compact for $0 \leqq \mu \leqq 1$ and $D_{n}$ contains only a finite number of eigenvalues. Now $\operatorname{dim} E_{n}(0) X=$ 1 and hence, $\operatorname{dim} E_{n}(1) X=1$ by induction. Thus there is exactly one point $\alpha_{n} \in \sigma(U)$ in $D_{n}$ and this $\alpha_{n}$ must be simple.

(vi) $\left|\alpha_{n}\right|=1$

Assume that $\left|\alpha_{n}\right|>1$. Then it follows that $\bar{\alpha}_{n}^{-1} \in D_{n}$. But due to (S) we find that $\bar{\alpha}_{n}^{-1} \in \sigma(U)$ and there will be two points belonging to $\sigma(U)$ in $D_{n}$. This is impossible.

Assume now that $\left|\alpha_{n}\right|<1$. If $\bar{\alpha}_{n}^{-1} \in D_{u}$ we can apply the same argument as above. If $\bar{\alpha}_{n}^{-1} \notin D_{n}$ it is easily seen that $\bar{\alpha}_{n}^{-1} \notin \sigma(U)$. In 
fact we show that if $\lambda \notin \bigcup_{1}^{\infty} D_{k}$ and $\lambda \neq 1$ it follows that $\lambda \notin \sigma(U)$. We need only consider $\lambda$ with $|\lambda|>1$. Let $D_{k}$ be the circle closest to $\lambda$. Then it is clear that $\left\{\lambda-\lambda_{n}|\geqq|\left|\lambda_{n}-\lambda_{k}\right|-r_{k} \mid\right.$ for all $n$ and we get

$$
K \sum_{1}^{\infty}\left\|W R_{\lambda}^{0} e_{n}\right\|^{2} \leqq K \sum_{1}^{\infty} b_{n}^{2}\left|\lambda-\lambda_{n}\right|^{-2} \leqq K \sum_{n=1}^{\infty} b_{n}^{2}\left(\left|\lambda_{n}-\lambda_{k}\right|-r_{k}\right)^{-2}<1
$$

due to (e). Hence $R_{\lambda}$ exists.

Now we have proved that $\sigma(U)$ consists of simple eigenvalues on the unit circle with limit point 1 . In the finite dimensional case it follows immediately that (3) is stable (see Boman [2]). In the infinite dimensional case we have to use condition $(f)$.

Put $E_{n}(0)=E_{n}$ and $E_{n}(1)=F_{n}$. If $F_{n} e_{n} \neq 0$ we put $\varphi_{n}=F_{n} e_{n}$ and if $F_{n} e_{n}=0$ we choose $\varphi_{n}$ as an arbitrary eigenvector of $U$ corresponding to $\alpha_{n}$. We have $E_{n} e_{n}=e_{n}$ and $U \varphi_{n}=\alpha_{n} \varphi_{n}$.

(vii) $\sum_{1}^{\infty}\left\|\varphi_{n}-e_{n}\right\|^{2}<\infty$,

$$
\left(F_{n}-E_{n}\right) e_{n}=(2 \pi i)^{-1} \int_{\sigma_{n}}\left(R_{\lambda}-R_{\lambda}^{0}\right) e_{n} d \lambda .
$$

A calculation shows that

$$
R_{\lambda}-R_{\lambda}^{0}=R_{\lambda}^{0}\left(I-W R_{\lambda}^{0}\right)^{-1} W R_{\lambda}^{0} .
$$

Thus

$$
\begin{aligned}
\left\|\left(F_{n}-E_{n}\right) e_{n}\right\| & \leqq(2 \pi)^{-1} \int_{\sigma_{n}}\left\|R_{\lambda}^{0}\right\| \cdot\left\|\left(I-W R_{\lambda}^{0}\right)^{-1}\right\| \cdot\left\|W R_{\lambda}^{0} e_{n}\right\| \cdot|d \lambda| \\
& \leqq(2 \pi)^{-1} r_{n}^{-1} \sup _{\lambda \in \sigma_{n}}\left(1-\left\|W R_{\lambda}^{0}\right\|\right)^{-1} \cdot K^{1 / 2} b_{n} r_{n}^{-1} 2 \pi r_{n} \\
& =\text { const } \cdot b_{n} r_{n}^{-1} .
\end{aligned}
$$

Here we used the fact that $\left\|R_{\lambda}^{0}\right\|=r_{n}^{-1}$ for all $\lambda \in c_{n}$. Then

$$
\sum_{1}^{\infty}\left\|\left(F_{n}-E_{n}\right) e_{n}\right\|^{2} \leqq \text { const. } \sum_{1}^{\infty} b_{n}^{2} r_{n}^{-2}<\infty \quad \text { due to (f). }
$$

It follows that $F_{n} e_{n}=0$ only for a finite number of $n$ and hence

$$
\sum_{1}^{\infty}\left\|\varphi_{n}-e_{n}\right\|^{2}<\infty \text {. }
$$

We define a linear operator $P$ by the relation $P x=\sum_{1}^{\infty} c_{\nu} \varphi_{\nu}$ where $x=\sum_{1}^{\infty} c_{\nu} e_{\nu}$ and $\sum_{1}^{\infty}\left|c_{\nu}\right|^{2}<\infty$. We recall that an operator $T$ is called injective if $T x=0$ implies $x=0$.

(viii) $I-P$ is compact and $P$ is injective. Hence $P^{-1}$ is continuous. 


$$
\sum_{1}^{\infty}\left\|(I-P) e_{n}\right\|^{2}=\sum_{1}^{\infty}\left\|e_{n}-\varphi_{n}\right\|^{2}<\infty \quad \text { due to (vii). }
$$

Thus $I-P$ belongs to the Schmidt class and is compact (see [5]). Assume now that $P x=\sum_{1}^{\infty} c_{\nu} \varphi_{\nu}=0$. We apply the projection $F_{k}$ and get

$$
F_{k} \sum_{1}^{\infty} c_{\nu} \varphi_{\nu}=c_{k} F_{k} \varphi_{k}=c_{k} \varphi_{k}=0
$$

and $c_{k}=0$ for every $k$. Hence $x=0$ and $P$ is injective.

Now we end the proof of the theorem. We have to estimate $\left\|U^{n} x\right\|$ for an arbitrary $x \in X$. Put $y=P^{-1} x$ and assume that $y=$ $\sum_{1}^{\infty} a_{\nu} e_{\nu}$. We get $x=P y=\sum_{1}^{\infty} a_{\nu} \varphi_{\nu}$ and

$$
U^{n} x=U^{n} P y=\sum_{1}^{\infty} a_{\nu} U^{n} \varphi_{\nu}=\sum_{1}^{\infty} a_{\nu} \alpha_{\nu}^{n} \varphi_{\nu}=P \sum_{1}^{\infty} a_{\nu} \alpha_{\nu}^{n} e_{\nu}
$$

Further

$$
\begin{aligned}
& \left\|U^{n} x\right\| \leqq\|P\| \cdot\left\{\sum_{1}^{\infty}\left|a_{\nu} \alpha_{\nu}^{n}\right|^{2}\right\}^{1 / 2}=\|P\| \cdot\left\{\sum_{1}^{\infty}\left|a_{\nu}\right|^{2}\right\}^{1 / 2} \\
& =\|P\| \cdot\|y\| \leqq\|P\| \cdot\left\|P^{-1}\right\| \cdot\|x\|,
\end{aligned}
$$

which implies that $\left\|U^{n}\right\| \leqq\|P\|\left\|P^{-1}\right\|$ for every $n$ and the proof is finished.

REMARK 4. If $C=\left(K \cdot \sum_{1}^{\infty} b_{n}^{2} r_{n}^{-2}\right)^{1 / 2}<2^{-1}$, then $\left\|U^{n}\right\|<(1-2 C)^{-1}$.

Proof. From the proof of (iii) it follows that $\left\|W R_{\lambda}^{0}\right\| \leqq C$ for all $\lambda \in \bigcup_{1}^{\infty} C_{k}$. Further we get

$$
\left\|\left(F_{n}-E_{n}\right) e_{n}\right\| \leqq(1-C)^{-1} K^{1 / 2} b_{n} r_{n}^{-1}<1
$$

for all $n$ since

$$
(1-C)^{-2} K \sum_{1}^{\infty} b_{n}^{2} r_{n}^{-2}=C^{2}(1-C)^{-2}<1
$$

Hence $F_{n} e_{n} \neq 0$ and $\varphi_{n}=F_{n} e_{n}$ for all $n$. Then

$$
\|I-P\|^{2} \leqq \sum_{1}^{\infty}\left\|\varphi_{\nu}-e_{\nu}\right\|^{2} \leqq C^{2}(1-C)^{-2}
$$

and

$$
\|P\| \leqq 1+C(1-C)^{-1}=(1-C)^{-1}
$$

Further 


$$
\left\|P^{-1}\right\|=\left\|(I-(I-P))^{-1}\right\| \leqq(1-\|I-P\|)^{-1} \leqq(1-C)(1-2 C)^{-1} .
$$

Finally

$$
\left\|U^{n}\right\| \leqq\|P\| \cdot\left\|P^{-1}\right\| \leqq(1-2 C)^{-1}
$$

An interesting application of the theorem is the second order equation

$$
y^{\prime \prime}+C(t) y=0
$$

in a Hilbert space $Y$, where $C(t)$ is selfadjoint. Put $X=Y \oplus Y$ and $u=\left(\begin{array}{l}y \\ y^{\prime}\end{array}\right)$. Then we get

$$
u^{\prime}=\left(\begin{array}{cc}
0 & I \\
-C(t) & 0
\end{array}\right) u
$$

This equation satisfies the symmetry condition (S) with $Q-\left(\begin{array}{rr}0 & I \\ -I & 0\end{array}\right)$.

Acknowledgements. I am very grateful to Professor G. Borg who proposed this problem and whose encouragement has been of great value to me.

\section{References}

1. G. Almkvist, Stability of differential equations in Banach algebras, Math. Scand. 14 (1964), 39-44.

2. J. Boman, On the stability of differential equations with periodic coefficients, Kungl. Takn. Högskolans handlingar, Stockholm, nr 180 (1961).

3. G. Borg, Coll. Int. des vibrations non linèaires, Iles de Proquerolles, 1951. Publ. Scient. Techn. Ministère de l'Aire, No. 281.

4. J. L. Massera-J. J. Schäffer, Linear differential equations and functional analysis, Ann. of Math. 67 (1958).

5. R. Schatten, Norm ideals of completely continuous operators, Springer Verlag 1960.

6. J. Schwartz, Perturbations of spectral operators and applications, Pacific J. Math. 4 (1954).

The Royal Institute of Technology, Stockholm.

AND

UNIVERSity of California, Berkeley 



\section{PACIFIC JOURNAL OF MATHEMATICS}

\section{EDITORS}

\author{
H. SAMmLSON \\ Stanford University \\ Stanford, California \\ R. M. BLUMENTHAL \\ University of Washington \\ Seattle, Washington 98105
}

\author{
*J. DUGUNDJI \\ University of Southern California \\ Los Angeles, California 90007
}

RICHARD ARENS

University of California

Los Angeles, California 90024

\section{E. F. BECKENBACH \\ B. H. NEUMANN \\ ASSOCIATE EDITORS}

\section{SUPPORTING INSTITUTIONS}

\author{
UNIVERSITY OF BRITISH COLUMBIA \\ CALIFORNIA INSTITUTE OF TECHNOLOGY \\ UNIVERSITY OF CALIFORNIA \\ MONTANA STATE UNIVERSITY \\ UNIVERSITY OF NEVADA \\ NEW MEXICO STATE UNIVERSITY \\ OREGON STATE UNIVERSITY \\ UNIVERSITY OF OREGON \\ OSAKA UNIVERSITY \\ UNIVERSITY OF SOUTHERN CALIFORNIA
}

\author{
STANFORD UNIVERSITY \\ UNIVERSITY OF TOKYO \\ UNIVERSITY OF UTAH \\ WASHINGTON STATE UNIVERSITY \\ UNIVERSITY OF WASHINGTON \\ * * * \\ AMERICAN MATHEMATICAL SOCIETY \\ CHEVRON RESEARCH CORPORATION \\ TRW SYSTEMS \\ NAVAL ORDNANCE TEST STATION
}

\footnotetext{
Mathematical papers intended for publication in the Pacific Journal of Mathematics should be typewritten (double spaced). The first paragraph or two must be capable of being used separately as a synopsis of the entire paper. It should not contain references to the bibliography. Manu. scripts may be sent to any one of the four editors. All other communications to the editors should be addressed to the managing editor, Richard Arens at the University of California, Los Angeles, California 90024.

50 reprints per author of each article are furnished free of charge; additional copies may be obtained at cost in multiples of 50 .
}

The Pacific Journal of Mathematics is published monthly. Effective with Volume 16 the price per volume (3 numbers) is $\$ 8.00$; single issues, $\$ 3.00$. Special price for current issues to individual faculty members of supporting institutions and to individual members of the American Mathematical Society: $\$ 4.00$ per volume; single issues $\$ 1.50$. Back numbers are available.

Subscriptions, orders for back numbers, and changes of address should be sent to Pacific Journal of Mathematics, 103 Highland Boulevard, Berkeley 8, California.

Printed at Kokusai Bunken Insatsusha (International Academic Printing Co., Ltd.), No. 6, 2-chome, Fujimi-cho, Chiyoda-ku, Tokyo, Japan.

PUBLISHED BY PACIFIC JOURNAL OF MATHEMATICS, A NON-PROFIT CORPORATION

The Supporting Institutions listed above contribute to the cost of publication of this Journal, but they are not owners or publishers and have no responsibility for its content or policies.

* Paul A. White, Acting Editor until J. Dugundji returns. 


\section{Pacific Journal of Mathematics}

\section{Vol. 16, No. $3 \quad$ BadMonth, 1966}

Gert Einar Torsten Almkvist, Stability of linear differential equations with

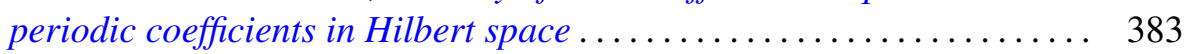

Richard Allen Askey and Stephen Wainger, A transplantation theorem for ultraspherical coefficients ................................ 393

Joseph Barback, Two notes on regressive isols .................. 407

Allen Richard Bernstein and Abraham Robinson, Solution of an invariant subspace problem of K. T. Smith and P. R. Halmos .............. 421

P. R. Halmos, Invariant subspaces of polynomially compact operators . . . . 433

Leon Bernstein, New infinite classes of periodic Jacobi-Perron algorithms.................................... 439

Richard Anthony Brualdi, Permanent of the direct product of matrices .... . 471

W. Wistar (William) Comfort and Kenneth Allen Ross, Pseudocompactness and uniform continuity in topological groups .................. 483

James Michael Gardner Fell, Algebras and fiber bundles . . . . . . . . . . . . 497

Alessandro Figà-Talamanca and Daniel Rider, A theorem of Littlewood and lacunary series for compact groups ..................... 505

David London, Two inequalities in nonnegative symmetric matrices...... 515

Norman Jay Pullman, Infinite products of substochastic matrices ........ 537

James McLean Sloss, Reflection and approximation by interpolation along

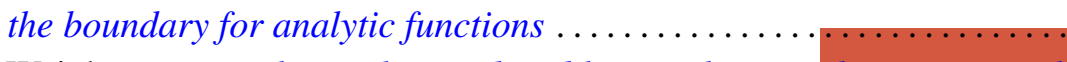

Carl Weinbaum, Visualizing the word problem, with an application to sixth groups................................... 